\title{
A descriptive analysis of drug treatment patterns and burden of illness for pediatric patients diagnosed with partial-onset seizures in the USA
}

This article was published in the following Dove Press journal:

Pediatric Health, Medicine and Therapeutics

2 December 2011

Number of times this article has been viewed

\author{
Mallik Angalakuditi' \\ Nupur Angalakuditi² \\ 'Georgia State University, Robinson \\ School of Business, Atlanta, GA, \\ ${ }^{2}$ New York Medical College, \\ Valhalla, NY, USA
}

Purpose: The objective of this retrospective claims study was to describe antiepileptic drug (AED) treatment patterns and burden of illness in children with epilepsy.

Methods: Data were administrative claims from a US commercial health plan. Patients were between 2 and 17 years of age and had one or more pharmacy claims for an oral AED from July 1, 2005, to November 30, 2009. The index date was defined as the first AED claim. Patients had one or more medical claims for epilepsy (ICD-9-CM 345.xx) during the 6-month pre-index period and were continuously enrolled for 12 months post index. Of the 17 AED medications used to identify patients, eleven medication cohorts had more than 100 patients: (1) carbamazepine (CAR); (2) clonazepam; (3) gabapentin (GAB); (4) lamotrigine (LAM); (5) levetiracetam (LEV); (6) oxcarbazepine (OXC); (7) phenobarbital; (8) phenytoin (PHY); (9) topiramate (TOP); (10) valproate (VAL); and (11) zonisamide (ZON).

Results: There were 3889 children who met the inclusion criteria. There were some differences in patients across the eleven AED treatment cohorts based on index therapy in age, gender, geographic location, Charlson comorbidity score, AHRQ comorbid conditions, as well as epilepsy-related risk factors and comorbidities. Of the 17 AEDs examined, the most frequently prescribed were OXC (21\%) and LEV (19\%); the least prescribed AED was GAB (1\%). Their respective mean post-index pharmacy and total costs were as follows: OXC, US\$2095 and US\$5556; LEV, US\$3025 and US\$9121; and GAB, US\$917 and US\$1597. The overall post-index mean pharmacy costs were US\$2637, and mean total costs were US\$6813.

Conclusion: Study results demonstrate differences in patient demographic and clinical characteristics across AED medication cohorts. Some cohorts have greater odds of a switch, or augmentation than the reference comparator CAR cohort. Variation was also observed in brand or generic medication use. LAM and TOP had the highest annual pharmacy costs of all the drugs.

Keywords: epilepsy, epidemiology, antiepileptic drugs, partial-onset seizure, pediatrics

\section{Introduction}

The incidence of epilepsy is significantly higher in children than in adults, with the highest incidence of seizures occurring during the first months and years of life. ${ }^{1,2}$ The increased susceptibility of childhood seizures is thought to be a factor of age: the enhanced excitability of the immature brain, which relates to the sequential development and expression of excitatory and inhibitory signaling pathways. ${ }^{3}$

During the early postnatal period, when the immature brain is highly susceptible to seizures, the primary inhibitory neurotransmitter gamma-aminobutyric acid (GABA) exerts a paradoxical excitatory action because of a large intracellular concentration
Correspondence: Mallik Angalakuditi Georgia State University, Robinson School of Business, Atlanta, GA, USA Tel +l 2037985150

Email hydmallik02@hotmail.com 
of chloride ions $\left(\mathrm{Cl}^{-}\right)$in immature neurons. ${ }^{4-9}$ Another cause of the increased susceptibility of the immature brain to seizures is the overabundance of excitatory N-methyl-Daspartate (NMDA) and alpha-amino-3-hydroxy-5-methyl-4isoxazolepropionic acid (AMPA) receptors. ${ }^{10-12}$ Therefore, the surplus of synaptic connections, the increased intracellular $\mathrm{Cl}^{-}$resulting in a depolarizing effect of GABA, and the overexpression of NMDA and AMPA receptors enhances the excitability of neuronal connections, and the lack of developed inhibitory networks leads to a situation where the immature brain is at high risk for seizures. ${ }^{3}$

Incidence of epilepsy is believed to be highest for populations under the age of 2 and over the age of 65 years. ${ }^{13}$ Of the estimated 200,000 new cases of epilepsy diagnosed in the United States each year, children under the age of 15 represent 45,000 of these cases. ${ }^{13}$ Generalized seizures are more common in children under the age of 10; afterwards more than half of all new cases of epilepsy will have partial seizures. ${ }^{13}$ Children with certain disabilities are believed to be at a higher risk for developing epilepsy, including children with mental retardation (25.8\%); children with cerebral palsy $(13 \%)$; children of mothers with epilepsy (8.7\%); and children of fathers with epilepsy $(2.4 \%){ }^{13}$

Similar to adults, antiepileptic drugs (AEDs) are usually the initial treatment for children, although management plans may include the use of multiple medications or various combinations of pharmacologic and nonpharmacologic therapies. AEDs are typically started when there is a significant likelihood that additional seizures will occur and when the seizures will cause potential physical, educational, or social harm. ${ }^{14}$ AEDs are prescribed based upon identified seizure type(s) and underlying causes. AEDs for partial seizure (monotherapy or adjunctive) include (1) carbamazepine (CAR); (2) clonazepam (CLO); (3) felbamate; (4) gabapentin (GAB); (5) lacosamide; (6) lamotrigine (LAM); (7) levetiracetam (LEV); (8) oxcarbazepine (OXC); (9) phenobarbital (PBL); (10) phenytoin (PHY); (11) pregabalin; (12) primidone; (13) tiagibine; (14) topiramate (TOP); (15) valproate (VAL); (16) vigabatrin; and (17) zonisamide. Surgery is considered when AEDs cannot control seizures or for seizures associated with structural brain abnormalities.

AEDs for children may be prescribed as tablets, sprinkles, capsules, or syrups. Epilepsy in children may be of short duration, easily controlled by medication, and eventually outgrown or, in other cases, it may be a life-long condition requiring long-term management. Also, epilepsy may sometimes be associated with other syndromes including infantile spasms, Lennox-Gastaut syndrome, genetically related conditions, and developmental disorders. ${ }^{15}$ Both early recognition and treatment are essential to the best possible outcomes, including the social impact, which is often severe in childhood. ${ }^{15}$

Other retrospective claims analyses of AED treatments have been performed on adult populations with epilepsy. ${ }^{16,17}$ However, there are no other studies that have studied AED treatment patterns in the pediatric population in the United States. The present study investigated differences in treatment patterns of AEDs prescribed and quantified the burden of illness associated with epilepsy in children.

\section{Methods}

This study was a retrospective analysis using medical and pharmacy claims from a large national US commercial health plan representing approximately 14 million members to measure AED treatment patterns. Patients were required to have at least one pharmacy claim for an oral AED indicated as monotherapy or adjunctive therapy for partial seizures and a diagnosis claim for any epilepsy seizure.

\section{Data source}

This retrospective observational study used medical and pharmacy claims (from July 2005 through November 2009) and enrollment information from a large managed health care plan. The health plan comprises discounted fee-for-service independent practice association plans spanning the United States. Approximately 13 million individuals with both medical and pharmacy benefit coverage were enrolled in the plan in 2009. These enrollees were geographically distributed across the United States, with the greatest representation in the South (51\%) and Midwest (27.4\%).

Medical claims data are collected from health care sites (inpatient hospital, outpatient hospital, emergency room, physician's office, surgery center, and other administering facilities) for specialty, preventive, and office-based treatments. Claims for ambulatory services submitted by individual physician providers use the HCFA-1500 format. Claims for facility services submitted by hospital institutions use the UB-82 or UB-92 format. Medical claims include multiple diagnosis codes recorded with the International Classification of Diseases, Ninth Revision, Clinical Modification (ICD9-CM) diagnosis codes; procedures recorded with ICD9-CM procedure codes, Current Procedural Terminology, or Health Care Financing Agency Common Procedure Coding System codes; site of service codes; provider specialty codes; revenue codes (for facilities); and paid amounts. Claims for pharmacy services are typically submitted electronically by 
the pharmacy at the time prescriptions are filled. The claims history is a profile of all outpatient prescription pharmacy services provided and covered by the health plan. All study data were de-identified in accordance with established privacy guidelines under the Health Insurance Portability and Accountability Act; therefore, a separate institutional review board approval was not required.

\section{Study population}

This study included commercial health plan members with epilepsy who were receiving treatment with an AED indicated for partial-onset seizures. To be included in the final study sample, patients had to meet the following inclusion criteria:

- One or more pharmacy claim for an oral AED indicated as monotherapy or adjunctive therapy for partial seizures during the identification period January 1, 2006, through November 30, 2008. The date of the first observed oral AED claim was defined as the index date and the medication was defined as the index AED.

- One or more medical claim with a primary diagnosis of epilepsy (ICD-9-CM diagnosis code 345.xx) during the pre-index period.

- Aged between 2 and 17 years as of the year of the preindex period.

- No medical claims with primary or secondary diagnoses for select other medical conditions (trigeminal neuralgia, postherpetic neuralgia, diabetic neuropathic pain, fibromyalgia) treated with AEDs during the pre-index or post-index periods.

\section{Epilepsy-related comorbid conditions}

Some conditions other than epilepsy are treated with AEDs and may also be prevalent epilepsy-related comorbid conditions. Patients who had diagnoses both for epilepsy and for epilepsy-related comorbidities as well as pharmacy claims for AEDs (indicated both for epilepsy and for epilepsy-related comorbidities) were not excluded from the study population. The epilepsy-related comorbidities included (1) depression and other mood disorders; (2) anxiety disorder; (3) childhood hyperkinetic syndrome (including attention deficit disorder); (4) migraine; (5) sleep disorder; (6) developmental/learning disability; and (7) epileptic psychosis, and associated risk factors.

\section{Medication cohorts}

Subjects were assigned to a study cohort based on the prescription-filled AED treatment. Of the 17 AED medications examined, medication cohorts were created for those that had more than 100 patients. Patients on monotherapy were assigned to the medication based on their index AED, while patients whose index AED treatment met the definition of polytherapy were assigned to one of five medication cohorts: (1) LAM; (2) LEV; (3) CAR; (4) PHY; and (5) CLO. These five cohorts were determined based on the distribution of polytherapy medications observed. The five most prevalent medications within the observed polytherapy AEDs determined the cohorts used. If a patient used more than one medication, the patient was assigned to the cohort with the most patients.

\section{Patient characteristics}

Demographic characteristics were determined from enrollment data and medical and pharmacy claims. During the 6-month baseline period, the following clinical characteristics were evaluated: epilepsy-related risk factors (as listed), Quan-Charlson comorbidity score, and the top five comorbid conditions as defined by the Agency for Healthcare Research and Quality. ${ }^{18,19}$

\section{Resource utilization and costs}

Health care resource utilization was calculated for ambulatory visits (office and outpatient), emergency department visits, and inpatient admissions. Health care costs were computed as the combined amounts paid by the health plan and the patient. Costs were calculated as total, medical, pharmacy, ambulatory, emergency services, inpatient, and other costs. Costs were adjusted using the annual medical care component of the consumer price index to reflect inflation between 2007 and 2009. Payments from other payers were estimated based on coordination of benefits information obtained by the health plan in its usual course of business.

\section{Analytic strategy}

All study variables, including baseline and outcome measures, were analyzed descriptively. Descriptive comparisons were made across cohorts. The analysis was performed with SAS (v 9; SAS Institute Inc., Cary, NC) and Stata software (v 9; StataCorp LP, College Station, TX).

\section{Results \\ Patient demographic and clinical characteristics}

Almost 900,000 commercial health plan enrollees with at least one pharmacy claim for an oral AED were identified in the database. Of those enrollees, 13,788 patients had at least one claim for epilepsy and had 18 months of continuous 
enrollment, and 3889 patients were aged between 2 and 17 years.

The average age of the patients was $10.08 \pm 4.46$ years, $53.8 \%$ were male, and $50.7 \%$ lived in the South. Of the AEDs used to treat epilepsy, 20.9\% of patients used OXC, 18.7\% used LEV, 17.2\% used LAM, and 17.1\% used VAL (see Table 1).

The majority (76.9\%) of the patients had a QuanCharlson comorbidity score of 0 . And, the overall mean Quan-Charlson comorbidity score was $0.40 \pm 0.84$, indicating patients had few comorbid conditions. Across the cohorts differences in the comorbidity score were observed, with the highest score in the CLO cohort $(0.95 \pm 1.05)$ and the lowest score in the VAL cohort $(0.23 \pm 0.60)$, although these differences are likely not of clinical significance (see Table 2). The two most prevalent epilepsy-related risk factors were developmental/learning disability and childhood hyperkinetic syndrome $(20.5 \%$ and $10.2 \%$, respectively) (see Table 3).

\section{Unadjusted treatment pattern analysis}

Most $(88 \%)$ of patients were on monotherapy. Patients on GAB, OXC, PBL, TOP, VAL, and ZON were only on monotherapy treatment; whereas, patients who received polytherapy (defined as (1) at least two fills of the AED that is filled on the index date ("index date" AED) within the first 90 days after the index date; (2) at least two fills of a second AED within the first 90 days after the index date; and (3) the second fill of the "index date" AED occurring after a fill of the second AED within 90 days of the index date) were in the remaining cohorts. Compliance with the index AED was measured using a medication possession ratio (MPR; calculated as the ratio of days' supply of the index medication to total days in the treatment period; the treatment period was the number of days between the index date and the earlier of (1) the first AED switch date or (2) the end of the post-index period). Patients using CAR had the highest MPR (mean 0.70; median 0.83), whereas CLO had the lowest (mean 0.32; median 0.16). Differences were also seen across the cohorts with respect to branded or generic AEDs used. Branded formulations of LEV, OXC, TOP, and VAL were used by more than $90 \%$ of patients taking those medications. Generic use for pediatric patients was predominantly in the PBL and CLO cohorts. Nearly $47 \%$ of all patients on monotherapy required dose escalation of their index medication, including $50 \%$ or more of patients taking LAM, LEV, or OXC (see Table 4).

Across all the cohorts, $12.8 \%$ of patients experienced at least one augmentation (minimum of one fill of a non-index AED with at least one subsequent fill of the index AED) to their index therapy, and $1.2 \%$ of patients had a second augmentation. Differences in augmentation were observed across the cohorts for both first and second augmentations. The percentage of patients augmenting their therapy ranged from $5.9 \%$ of the CAR cohort to $25 \%$ of the PHY cohort. This pattern was also observed for the second augmentation (see Table 5).

Switching (at least one fill of a non-index AED with no subsequent fills of the index AED) occurred in just over $10 \%$ of patients with differences across the cohorts, whereas just over $2 \%$ had a second switch from their index AED treatment. The PHY cohort showed the greatest percentage of patients with a first switch $(28.0 \%)$, and the least switches occurred in the VAL cohort (7.1\%) (Table 5).

Furthermore, on average less than $11 \%$ of patients changed from brand to generic formulations of AED

Table I Patient demographic by medication cohort

\begin{tabular}{|c|c|c|c|c|c|c|c|c|c|}
\hline \multirow[t]{2}{*}{ Drug category } & \multicolumn{2}{|c|}{ Cohort } & \multicolumn{2}{|c|}{ Age (years) } & \multirow{2}{*}{$\begin{array}{l}\text { Gender } \\
\text { Male (\%) }\end{array}$} & \multicolumn{4}{|l|}{ Region } \\
\hline & $\mathbf{n}$ & $\%$ & Mean & SD & & Northeast (\%) & Midwest (\%) & South (\%) & West (\%) \\
\hline Total & 3889 & 100 & 10.08 & 4.46 & 53.82 & 9.98 & 27.41 & 50.71 & 11.91 \\
\hline CAR & 388 & 9.98 & 10.22 & 4.23 & 54.64 & 9.28 & 32.73 & 44.85 & 13.14 \\
\hline CLO & 93 & 2.39 & 9.61 & 4.73 & 72.04 & 11.83 & 21.51 & 49.46 & 17.20 \\
\hline GAB & 37 & 0.95 & 12.00 & 3.89 & 40.54 & 8.11 & 21.62 & 64.86 & 5.41 \\
\hline LAM & 667 & 17.15 & II.08 & 4.17 & 43.63 & 10.19 & 28.04 & 47.23 & 14.54 \\
\hline LEV & 728 & 18.72 & 9.36 & 4.72 & 52.47 & 9.75 & 28.16 & 51.65 & 10.44 \\
\hline OXC & 814 & 20.93 & 9.04 & 4.25 & 58.60 & 9.46 & 21.87 & 57.99 & 10.69 \\
\hline PBL & 51 & $|.3|$ & 5.49 & 4.17 & 41.18 & 11.76 & 21.57 & 49.02 & 17.65 \\
\hline $\mathrm{PHY}$ & 100 & 2.57 & 12.00 & 4.77 & 56.00 & 17.00 & 26.00 & 50.00 & 7.00 \\
\hline TOP & 225 & 5.79 & 10.84 & 4.75 & 43.56 & II.II & 30.67 & 48.89 & 9.33 \\
\hline VAL & 665 & 17.10 & 10.68 & 3.97 & 63.61 & 10.23 & 32.78 & 44.21 & 12.78 \\
\hline ZON & 121 & 3.11 & 10.84 & 4.68 & 42.15 & 4.96 & 14.05 & 71.07 & 9.92 \\
\hline
\end{tabular}

Abbreviations: CAR, carbamazepine; CLO, clonazepam; GAB, gabapentin; LAM, lamotrigine; LEV, levetiracetam; OXC, oxcarbazepine; PBL, phenobarbital; PHY, phenytoin; $\mathrm{SD}$, standard deviation; TOP, topiramate; VAL, valproate; ZON, zonisamide. 
Table 2 Quan-Charlson comorbidity scores

\begin{tabular}{|c|c|c|c|c|c|c|c|}
\hline \multirow[t]{2}{*}{ Drug category } & \multirow{2}{*}{$\begin{array}{l}\text { Quan-Charlson } \\
\text { comorbidity score } \pm \text { SD }\end{array}$} & \multicolumn{6}{|c|}{ Number and percentage } \\
\hline & & 0 & $\mathbf{I}$ & 2 & 3 & 4 & $5+$ \\
\hline Total $(n=3889)$ & $0.40 \pm 0.84$ & $2990(76.88 \%)$ & 388 (9.98\%) & $395(10.16 \%)$ & 93 (2.39\%) & $14(0.36 \%)$ & $9(0.23 \%)$ \\
\hline $\operatorname{CAR}(n=388)$ & $0.43 \pm 0.85$ & $298(76.80 \%)$ & $28(7.22 \%)$ & $49(12.63 \%)$ & $12(3.09 \%)$ & $\mathrm{I}(0.26 \%)$ & 0 \\
\hline CLO $(n=93)$ & $0.95 \pm 1.05$ & 46 (49.46\%) & $13(13.98 \%)$ & 27 (29.03\%) & 7 (7.53\%) & 0 & 0 \\
\hline GAB $(n=37)$ & $0.43 \pm 1.24$ & 29 (78.38\%) & $5(|3.5| \%)$ & $2(5.41 \%)$ & 0 & 0 & I (2.70\%) \\
\hline LAM $(n=667)$ & $0.35 \pm 0.75$ & 529 (79.31\%) & 57 (8.55\%) & 67 (10.04\%) & $13(1.95 \%)$ & I (0.15\%) & 0 \\
\hline $\operatorname{LEV}(n=728)$ & $0.55 \pm 1.07$ & $526(72.25 \%)$ & 78 ( $10.7 \mid \%)$ & $82(11.26 \%)$ & 27 (3.7I\%) & $9(1.24 \%)$ & $6(0.82 \%)$ \\
\hline $\mathrm{OXC}(\mathrm{n}=8 \mid 4)$ & $0.35 \pm 0.77$ & $64 \mathrm{I}(78.75 \%)$ & $82(10.07 \%)$ & 74 (9.09\%) & $14(1.72 \%)$ & I (0.12\%) & $2(0.25 \%)$ \\
\hline $\operatorname{PBL}(n=5 I)$ & $0.71 \pm 0.99$ & $31(60.78 \%)$ & 7 (13.73\%) & $10(19.61 \%)$ & $3(5.88 \%)$ & 0 & 0 \\
\hline $\mathrm{PHY}(\mathrm{n}=100)$ & $0.53 \pm 0.87$ & $67(67.0 \%)$ & 17 (17.0\%) & $13(13.0 \%)$ & $2(2.0 \%)$ & I (I.0\%) & 0 \\
\hline TOP $(n=225)$ & $0.44 \pm 0.78$ & I60 (7I.II\%) & 38 (I6.89\%) & $22(9.78 \%)$ & $4(1.78 \%)$ & I (0.44\%) & 0 \\
\hline $\operatorname{VAL}(\mathrm{n}=665)$ & $0.23 \pm 0.60$ & 566 (85.11\%) & 53 (7.97\%) & 39 (5.86\%) & 7 (1.05\%) & 0 & 0 \\
\hline $\operatorname{ZON}(n=121)$ & $0.35 \pm 0.77$ & 97 (80.17\%) & 10 (8.26\%) & 10 (8.26\%) & $4(3.31 \%)$ & 0 & 0 \\
\hline
\end{tabular}

Abbreviations: CAR, carbamazepine; CLO, clonazepam; GAB, gabapentin; LAM, lamotrigine; LEV, levetiracetam; OXC, oxcarbazepine; PBL, phenobarbital; PHY, phenytoin; SD, standard deviation; TOP, topiramate; VAL, valproate; ZON, zonisamide.

treatment or vice versa during the observation period. Although patients had 0.73 mean AED medications during the baseline period, the mean increased to 1.5 medications during the follow-up period. Patients receiving CLO were taking the most AEDs during baseline (mean 1.5) and follow-up (mean 2.3) (see Table 5).

\section{Burden of Illness}

The majority of patients in the cohorts had on average $3.33 \pm 5.81$ ambulatory visits (CAR, GAB, PBL, and VAL fewer than three visits), and patients in the LAM cohort had the most ambulatory visits of $3.93 \pm 7.84$. Cohorts also had differences for the number of inpatient admissions, although largely patients averaged under one stay during the follow-up period (see Table 6).
Epilepsy-related costs varied across the medication cohorts. Patients in the CLO cohort had on average the highest medical costs (US\$7774.31 $\pm 17,694.68$ ), comprising ambulatory (US\$1726.32 \pm 4920.78 ), inpatient (US\$5392.02 $\pm 15,425.93)$, and other medical costs (US\$635.69 \pm 3311.88 ). Lowest medical and ambulatory costs were in the GAB cohort (US\$680.46 \pm 1531.97 and US\$466.39 \pm 746.39 , respectively). On average, the PBL cohort had the lowest inpatient costs (US\$184.50 \pm 947.50 ) and GAB had the lowest other medical costs (US\$0). Pharmacy costs were highest in the LAM cohort (US\$5440.70 \pm 4206.83 ) and lowest for PBL (US\$301.58 \pm 618.37 ). Epilepsy-related total costs were highest for LAM patients (US\$11,430.41 $\pm 36,912.43$ ) and were lowest for PBL (US\$1027.07 \pm 1691.31 ) (see Table 7).

Table 3 Epilepsy-related risk factors and comorbidities

\begin{tabular}{|c|c|c|c|c|c|c|c|c|c|c|c|c|c|c|c|c|}
\hline & \multicolumn{2}{|c|}{$\begin{array}{l}\text { Anxiety } \\
\text { disorder }\end{array}$} & \multicolumn{2}{|c|}{$\begin{array}{l}\text { Cognitive } \\
\text { impairment }^{\mathrm{a}}\end{array}$} & \multicolumn{2}{|c|}{ Depression $^{\text {b }}$} & \multicolumn{2}{|c|}{$\begin{array}{l}\text { Developmental/ } \\
\text { learning } \\
\text { disability }\end{array}$} & \multicolumn{2}{|c|}{$\begin{array}{l}\text { Epileptic } \\
\text { psychosis }\end{array}$} & \multicolumn{2}{|c|}{$\begin{array}{l}\text { Hyperkinetic } \\
\text { syndrome of } \\
\text { childhood }^{\text {a }}\end{array}$} & \multicolumn{2}{|c|}{ Migraine } & \multicolumn{2}{|c|}{$\begin{array}{l}\text { Sleep } \\
\text { disorder }\end{array}$} \\
\hline & $\mathbf{n}$ & $\%$ & $\mathbf{n}$ & $\%$ & $\mathbf{n}$ & $\%$ & $\mathbf{n}$ & $\%$ & $\mathbf{n}$ & $\%$ & $\mathbf{n}$ & $\%$ & $\mathbf{n}$ & $\%$ & $\mathbf{n}$ & $\%$ \\
\hline Total & $|4|$ & 3.63 & 43 & I.II & 162 & 4.17 & 796 & 20.47 & 2 & 0.05 & 397 & 10.21 & 162 & 4.17 & 182 & 4.68 \\
\hline CAR & 14 & 3.61 & NR & NR & 9 & 2.32 & 79 & 20.36 & I & 0.26 & 40 & 10.31 & 6 & 1.55 & 12 & 3.09 \\
\hline CLO & 6 & 6.45 & 5 & 5.38 & 6 & 6.45 & 48 & 51.61 & I & 1.08 & 7 & 7.53 & I & 1.08 & 13 & 13.98 \\
\hline GAB & - & - & NR & NR & I & 2.70 & 5 & $13.5 \mid$ & NR & NR & 5 & $|3.5|$ & 7 & 18.92 & 2 & $5.4 I$ \\
\hline LAM & 28 & 4.20 & 7 & 1.05 & 35 & 5.25 & 148 & 22.19 & NR & NR & 73 & 10.94 & 15 & 2.25 & 34 & 5.10 \\
\hline LEV & 16 & 2.20 & 14 & 1.92 & 19 & 2.61 & 172 & 23.63 & NR & NR & 56 & 7.69 & 28 & 3.85 & 35 & 4.81 \\
\hline OXC & 22 & 2.70 & 4 & 0.49 & 23 & 2.83 & 122 & 14.99 & NR & NR & 77 & 9.46 & 15 & 1.84 & 38 & 4.67 \\
\hline PBL & NR & NR & NR & NR & NR & NR & 22 & 43.14 & NR & NR & NR & NR & NR & NR & 4 & 7.84 \\
\hline PHY & 4 & 4.00 & NR & NR & 5 & 5.00 & 19 & 19.00 & NR & NR & 10 & 10.00 & 4 & 4.00 & I & 1.00 \\
\hline TOP & 18 & 8.00 & 3 & 1.33 & 16 & 7.11 & 43 & 19.11 & NR & NR & 12 & 5.33 & 48 & 21.33 & 13 & 5.78 \\
\hline VAL & 29 & 4.36 & 8 & 1.20 & 43 & 6.47 & 113 & 16.99 & NR & NR & 106 & 15.94 & 35 & 5.26 & 27 & 4.06 \\
\hline ZON & 4 & 3.31 & 2 & 1.65 & 5 & 4.13 & 25 & 20.66 & NR & NR & II & 9.09 & 3 & 2.48 & 3 & 2.48 \\
\hline
\end{tabular}

Notes: alncluding attention deficit disorder; bincluding other mood disorders.

Abbreviations: CAR, carbamazepine; CLO, clonazepam; GAB, gabapentin; LAM, lamotrigine; LEV, levetiracetam; NR, not reported; OXC, oxcarbazepine; PBL, phenobarbital; $\mathrm{PHY}$, phenytoin; TOP, topiramate; VAL, valproate; ZON, zonisamide. 
Table 4 Antiepileptic drug treatment patterns: I

\begin{tabular}{|c|c|c|c|c|c|c|c|c|c|c|c|c|c|}
\hline \multirow[t]{2}{*}{$\begin{array}{l}\text { Medication } \\
\text { cohort }\end{array}$} & \multicolumn{2}{|c|}{ Monotherapy } & \multicolumn{2}{|c|}{ Polytherapy } & \multicolumn{3}{|c|}{ Compliance (MPR) } & \multicolumn{2}{|c|}{ Branded use } & \multicolumn{2}{|c|}{ Generic use } & \multicolumn{2}{|c|}{$\begin{array}{l}\text { Dose } \\
\text { escalation* }\end{array}$} \\
\hline & $\mathbf{n}$ & $\%$ & $\mathbf{n}$ & $\%$ & Mean & Median & SD & $\mathbf{n}$ & $\%$ & $\mathbf{n}$ & $\%$ & $\mathbf{n}$ & $\%$ \\
\hline Total & 3424 & 88.04 & 465 & 11.96 & 0.66 & 0.79 & 0.31 & NR & NR & NR & NR & 1602 & 46.79 \\
\hline CAR & 360 & 92.78 & 28 & 7.22 & 0.70 & 0.83 & 0.30 & 227 & 63.06 & 133 & 36.94 & 139 & 38.61 \\
\hline CLO & 39 & 41.94 & 54 & 58.06 & 0.32 & 0.16 & 0.35 & 2 & 5.13 & 37 & 94.87 & 8 & 20.51 \\
\hline GAB & 37 & 100.00 & NR & NR & 0.48 & 0.36 & 0.34 & II & 29.73 & 26 & 70.27 & 14 & 37.84 \\
\hline LAM & 481 & 72.11 & 186 & 27.89 & 0.70 & 0.83 & 0.29 & 362 & 75.26 & 119 & 24.74 & 275 & 57.17 \\
\hline LEV & 554 & 76.10 & 174 & 23.90 & 0.65 & 0.78 & 0.32 & 552 & 99.64 & 2 & 0.36 & 277 & 50.00 \\
\hline OXC & 814 & 100.00 & NR & NR & 0.68 & 0.80 & 0.30 & 754 & 92.63 & 60 & 7.37 & 417 & 51.23 \\
\hline PBL & 51 & 100.00 & NR & NR & 0.57 & 0.71 & 0.36 & NR & NR & 51 & 100.00 & 18 & 35.29 \\
\hline PHY & 77 & 77.00 & 23 & 23.00 & 0.39 & 0.28 & 0.34 & 40 & 51.95 & 37 & 48.05 & 24 & 31.17 \\
\hline TOP & 225 & 100.00 & NR & NR & 0.60 & $0.7 \mathrm{I}$ & 0.33 & 225 & 100.00 & NR & NR & 110 & 48.89 \\
\hline VAL & 665 & 100.00 & NR & NR & 0.69 & 0.81 & 0.29 & 611 & 91.88 & 54 & 8.12 & 265 & 39.85 \\
\hline ZON & 121 & 100.00 & NR & NR & 0.63 & 0.77 & 0.34 & 43 & 35.54 & 78 & 64.46 & 55 & 45.45 \\
\hline
\end{tabular}

Note: *For all monotherapy patients $(\mathrm{n}=2424)$.

Abbreviations: CAR, carbamazepine; CLO, clonazepam; GAB, gabapentin; LAM, lamotrigine; LEV, levetiracetam; MPR, medication possession ratio; NR, not reported; OXC, oxcarbazepine; PBL, phenobarbital; PHY, phenytoin; SD, standard deviation; TOP, topiramate; VAL, valproate; ZON, zonisamide.

\section{Discussion}

This study involved commercial health plan members between 2 and 17 years of age, who were prescribed with at least one AED, and were diagnosed with epilepsy. The identification criteria were planned to observe treatment patterns of AED in children with epilepsy.

Of the 3889 children identified, it was observed that overall $88 \%$ received monotherapy. Across the cohorts, monotherapy was observed for patients in the $\mathrm{GAB}, \mathrm{OXC}$, PBL, TOP, VAL, and ZON cohorts, whereas patients in the remaining cohorts received both monotherapy and polytherapy. A recent Swedish population-based study of children diagnosed with epilepsy found that at the end of the
10 -year study period AED monotherapy was used by $64.4 \%$ of the population. ${ }^{20}$ The high number of patients receiving monotherapy, suggests that the US pediatric patients may be well managed or that physicians are generally hesitant to prescribe more than one AED to children.

In addition, a recent review of an adult population suggested the potential benefits of monotherapy included fewer adverse events and better tolerability, avoidance of drug-drug interactions, reduced treatment costs, and improved compliance. ${ }^{21}$ The authors of the study also concluded that because of the lack of conclusive evidence of better seizure control with polytherapy, in the majority of patients, some patients may benefit from conversion to monotherapy. ${ }^{21}$ The

Table 5 Antiepileptic drug (AED) treatment patterns: II

\begin{tabular}{|c|c|c|c|c|c|c|c|c|c|c|c|c|c|c|}
\hline \multirow[t]{2}{*}{$\begin{array}{l}\text { Medication } \\
\text { cohort }\end{array}$} & \multicolumn{2}{|c|}{$\begin{array}{l}\text { First } \\
\text { augmentation }\end{array}$} & \multicolumn{2}{|c|}{$\begin{array}{l}\text { Second } \\
\text { augmentation }\end{array}$} & \multicolumn{2}{|c|}{ First switch } & \multicolumn{2}{|c|}{ Second switch } & \multicolumn{2}{|c|}{$\begin{array}{l}\text { Change in } \\
\text { branded/generic }\end{array}$} & \multicolumn{2}{|c|}{$\begin{array}{l}\text { Count of } \\
\text { AEDs during } \\
\text { baseline }\end{array}$} & \multicolumn{2}{|c|}{$\begin{array}{l}\text { Count of } \\
\text { AEDs during } \\
\text { follow-up }\end{array}$} \\
\hline & $\mathbf{n}$ & $\%$ & $\mathbf{n}$ & $\%$ & $\mathbf{n}$ & $\%$ & $\mathbf{n}$ & $\%$ & $\mathbf{n}$ & $\%$ & Mean & SD & Mean & SD \\
\hline Total & 498 & $\mid 2.81$ & 46 & 1.18 & 444 & 11.42 & 89 & 2.29 & 412 & 10.59 & 0.73 & 0.88 & 1.51 & 0.89 \\
\hline CAR & 23 & 5.93 & 2 & 0.52 & 47 & 12.11 & 3 & 0.77 & 37 & 9.54 & 0.79 & 0.64 & 1.34 & 0.71 \\
\hline CLO & 17 & 18.28 & 2 & 2.15 & 10 & 10.75 & 2 & 2.15 & 3 & 3.23 & 1.48 & 1.25 & 2.31 & 1.15 \\
\hline GAB & 3 & 8.11 & NR & $N R$ & 4 & 10.81 & 1 & 2.70 & 2 & 5.41 & 0.59 & 0.69 & 1.27 & 0.65 \\
\hline LAM & 111 & 16.64 & 11 & 1.65 & 71 & 10.64 & 15 & 2.25 & 115 & 17.24 & 1.02 & 1.10 & 1.74 & 0.99 \\
\hline LEV & 113 & 15.52 & 7 & 0.96 & 101 & 13.87 & 23 & 3.16 & 94 & $12.9 \mid$ & 0.74 & 1.08 & 1.75 & 1.03 \\
\hline OXC & 87 & 10.69 & 7 & 0.86 & 75 & 9.21 & 23 & 2.83 & 47 & 5.77 & 0.50 & 0.60 & 1.30 & 0.72 \\
\hline PBL & 7 & 13.73 & I & 1.96 & 6 & 11.76 & 1 & 1.96 & NR & NR & 0.73 & 0.63 & 1.33 & 0.62 \\
\hline PHY & 25 & 25.00 & 5 & 5.00 & 28 & 28.00 & 3 & 3.00 & 15 & 15.00 & 0.66 & 1.13 & 2.05 & 1.15 \\
\hline TOP & 32 & 14.22 & 6 & 2.67 & 37 & 16.44 & 7 & 3.11 & 11 & 4.89 & 0.65 & 0.73 & 1.43 & 0.77 \\
\hline VAL & 60 & 9.02 & 5 & 0.75 & 47 & 7.07 & 7 & 1.05 & 53 & 7.79 & 0.62 & 0.63 & 1.12 & 0.61 \\
\hline ZON & 20 & 16.53 & NR & NR & 18 & |4.88 & 4 & 3.31 & 35 & 28.93 & 0.70 & 0.76 & 1.45 & 0.77 \\
\hline
\end{tabular}

Abbreviations: CAR, carbamazepine; CLO, clonazepam; GAB, gabapentin; LAM, lamotrigine; LEV, levetiracetam; NR, not reported; OXC, oxcarbazepine; PBL, phenobarbital; PHY, phenytoin; SD, standard deviation; TOP, topiramate; VAL, valproate; ZON, zonisamide. 


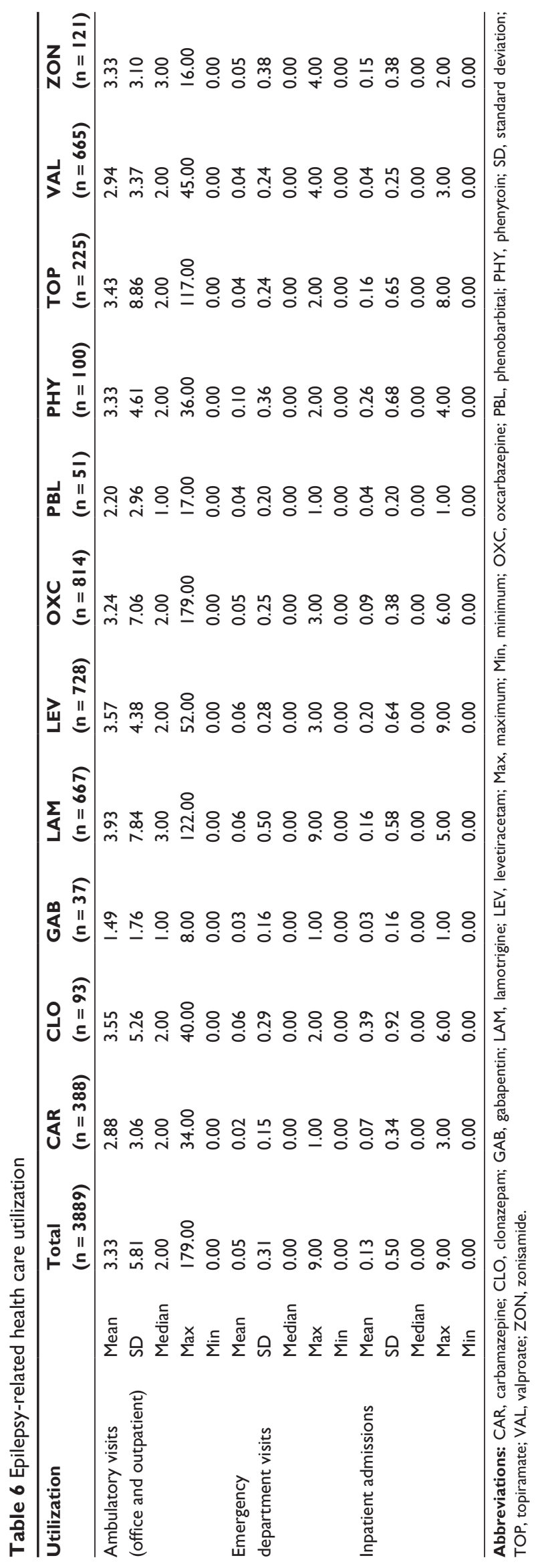

benefits of monotherapy described in the adult population may also be possible in the pediatric population.

Furthermore, the present study found there were differences among medication cohorts for adherence. Adherence is commonly agreed to be an MPR of 0.80 or greater. The mean and median MPR was highest for CAR (mean 0.70; median 0.83) and LAM (mean 0.70; median 0.83); MPR was lowest for CLO (mean 0.32; median 0.16). On average, the mean and median MPR for the index AEDs was 0.66 and 0.79 . One recent study of a pediatric population (mean age 7.2 years) investigated the reliability of parent-reported adherence over a 3-month period compared with electronically monitored adherence. ${ }^{22}$ The study found electronic adherence was $80.3 \%$, compared with parentreported adherence at $96.5 \%$. A second study on pediatric AED compliance found that adherence across the first month of therapy was $79.4 \% .{ }^{23}$ Interestingly, this paper also reported that adherence was almost $90 \%$ in the first 5 days, dropping to approximately $85 \%$ by days 6 and 7 , then generally at or below $80 \%$ thereafter. Another study, which surveyed an adolescent population, found that $35 \%$ of adolescents reported they had been nonadherent to their AED medication in the prior month. ${ }^{24}$ While the current authors' MPR data is derived from fills observed in pharmacy claims, the data from these studies are comparable with what is reported in the present study, with a median MPR (0.79) considered to be compliant or nearly compliant for over half of the AEDs.

In terms of changing between brand and generic medications, many frequently prescribed brand-name AEDs are approaching the end of their patent protection, and generic versions have been approved for the market. A controversial issue of changing between brand-name and generic AEDs has become an important topic in the clinical community. ${ }^{25}$ A recent meta-analysis included nine randomized controlled trials comparing seizure-related outcomes with use of brand-name and generic versions of AEDs in an adult population. ${ }^{26-35}$ None of these studies found the brandname AED to be superior or inferior to the generic AED in controlling seizures. In the present study, although the authors observed a difference between medication cohorts for change between brand-name or generic medications, the rate of change was only $10 \%$ on average.

Dose escalation of an index medication may be indicative of titration or need for better control of epilepsy. In the present study, nearly half of all patients on monotherapy required dose escalation of their index medication. In addition, treatment failure may also be indicated by augmentation or switching of the index medication, and this was seen to 


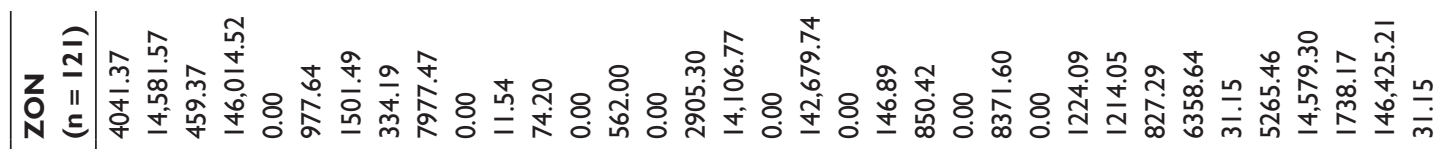

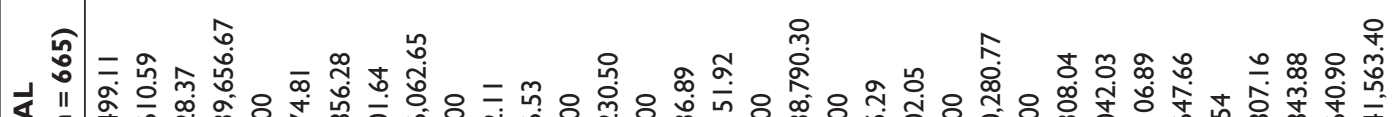
>

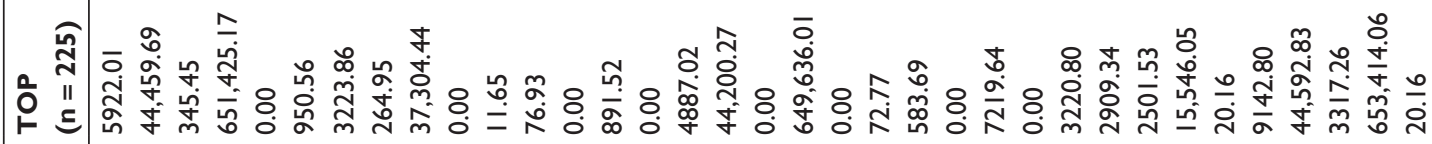

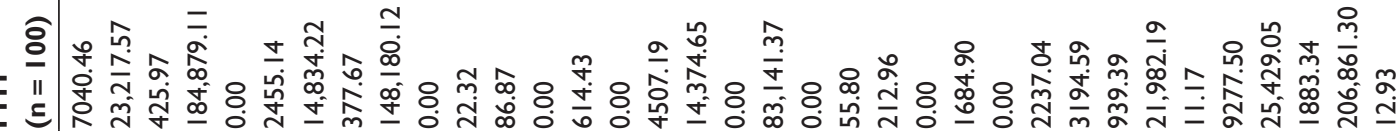
นิ

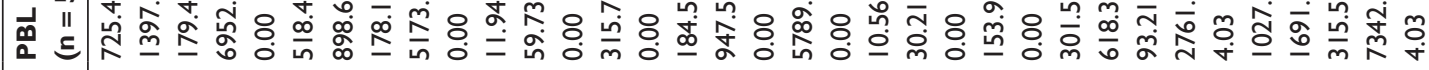

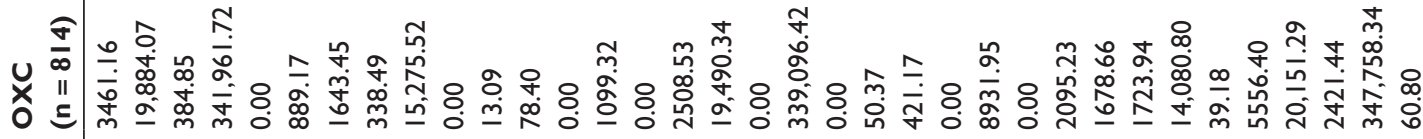

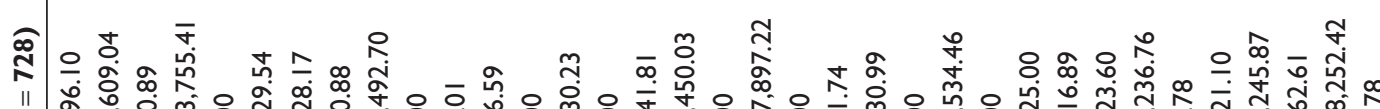

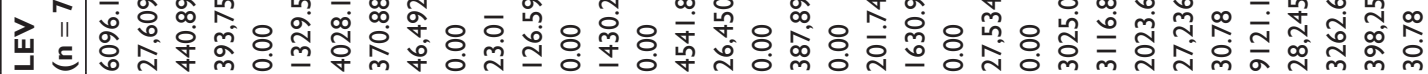

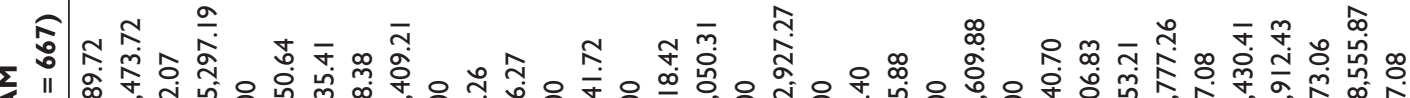
J

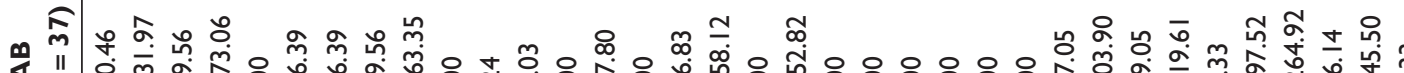

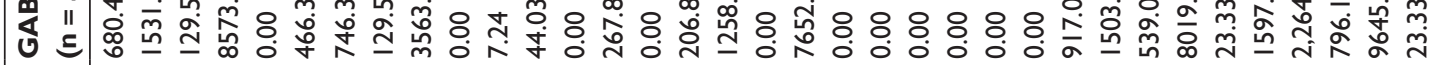
○ $\frac{\frac{n}{d}}{\overline{\frac{0}{0}}}$

悉 Uీ

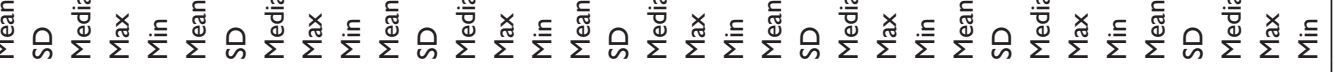


occur more often for some AED medications than others. For example, the percentage of patients who experienced a first augmentation was lowest for CAR (5.9\%) and VAL (9.0\%) and highest for PHY (25.0\%) and CLO (18.3\%). In addition, the percentage of patients who experienced a first switch was lowest for VAL (7.1\%) and OXC (9.2\%) and highest for PHY (28.0\%) and TOP (16.4\%). Therefore, index medications such as VAL with both low rates of first augmentation and first switch compared with the other index AEDs can be seen as a highly successful treatment, whereas index medications such as PHY with both high rates of first augmentation and first switch can be seen as a less successful AED treatment.

Other factors may influence medication success. Several of the observed patient demographic and clinical characteristics were seen to influence treatment failure in the present study. For example, age and gender were seen to increase the rate of first switch, depression and developmental/learning disabilities were seen to influence first augmentation, and age was seen to be a factor for influencing an increase in change from brand-name or generic medication. Side effects are another consideration in terms of influence on switch, augmentation, or change from brand-name or generic medication; however, this factor was not measured in the present analysis.

Treatment-related differences were looked for in health care utilization and costs. LAM, OXC, VAL, and LEV were among the most commonly used AEDs, followed by CAR. CLO, GAB, ZON, PHY, and PBL were administered in less than $20 \%$ each of the sample population. Nevertheless, both the mean and the median total annual epilepsy-related health care costs for VAL and CAR cohorts were less than half of that associated with the more commonly used AEDs (LAM and LEV). The epilepsy-related ambulatory and pharmacy costs incurred by the $\mathrm{ZON}$ cohort were comparable with those of CAR, but the overall total epilepsy costs were much higher than for CAR.

Finally, several limitations relating to the use of claims data should be considered when interpreting the results of the present study. Claims data are collected for payment, not for research, and are subject to possible coding errors. A diagnosis code may be included as a rule-out criterion and does not necessarily indicate disease presence. Although the present analysis focused on treatment for partial-onset seizures, other seizure types were not excluded: patients could experience more than one type of seizure. In addition, we cannot assess epilepsy severity or how long a patient has been receiving treatment for epilepsy. Also, a prescription claim does not necessarily mean a drug was taken as prescribed, and some patients may receive drugs without a prescription claim (eg, by receiving samples). Claims data do not contain information on disease severity, and it is possible that patients in some cohorts had more severe disease than patients in other cohorts. Finally, there are limitations to the generalizability of this study. The data used for this study came from a managed care population and may not be applicable to the entire US population. However, the health plans used for analysis in this study include a wide geographic distribution of patients and should be generalizable to managed care populations on a national level. All the medications, both brand-name and generic, that are currently available in the United States are also available in many other countries. However, the actual treatment patterns and burden of illness of epilepsy may vary slightly from country to country because of different health care systems and different health plan member benefits.

\section{Conclusion}

The results of this study demonstrate there were differences between patient demographics and clinical characteristics across AED medication cohorts. Some cohorts had greater odds of a switch or augmentation than the reference comparator CAR cohort. Variation was also observed in brand-name or generic medication use. LAM and TOP had the highest annual pharmacy costs of all the drugs.

\section{Disclosure}

The authors report no conflicts of interest in this work.

\section{References}

1. Holmes GL. The 2008 Judith Hoyer Lecture: epilepsy in children; listening to mothers. Epilepsy Behav. 2009;16(2):193-202.

2. Hauser WA. The prevalence and incidence of convulsive disorders in children. Epilepsia.1994;35 Supp1 2:S1-S6.

3. Khazipov R, Esclapez M, Caillard O, et al. Early development of neuronal activity in the primate hippocampus in utero. $J$ Neurosci. 2001;21(24): 9770-9781.

4. Khazipov R, Khalilov I, Tyzio R, Morozova E, Ben-Ari Y, Holmes GL. Developmental changes in GABAergic actions and seizure susceptibility in the rat hippocampus. Eur J Neurosci. 2004;19(3):590-600.

5. Jensen FE, Baram TZ. Developmental seizures induced by common early-life insults: short- and long-term effects on seizure susceptibility. Ment Retard Dev Disabil Res Rev. 2000;6(4):253-257.

6. Dzhala VI, Staley KJ. Transition from interictal to ictal activity in limbic networks in vitro. J Neurosci. 2003;23(21):7873-7880.

7. Ben-Ari Y, Cherubini E, Corradetti R, Galarsa JL. Giant synaptic potentials in immature rat CA3 hippocampal neurones. $J$ Physiol. 1989;416:303-325.

8. Ben-Ari Y. Excitatory actions of GABA during development: the nature of the nurture. Nat Rev Neurosci. 2002;3(9):728-739.

9. Ben-Ari Y, Holmes GL. The multiple facets of gamma-aminobutyric acid dysfunction in epilepsy. Curr Opin Neurol. 2005;18(2): $141-145$. 
10. Miller LP, Johnson AE, Gelhard RE, Insel TR. The ontogeny of excitatory amino acid receptors in the rat forebrain: II. Kainic acid receptors. Neuroscience. 1990;35(1):45-51.

11. McDonald JW, Johnston MV, Young AB. Differential ontogenic development of three receptors comprising the NMDA receptor/channel complex in the rat hippocampus. Exp Neurol. 1990;110(3):237-247.

12. Silverstein FS, Jensen FE. Neonatal seizures. Ann Neurol. 2007;62(2): 112-120.

13. Epilepsy Foundation. Epilepsy and seizure statistics. Available from: http://www.epilepsyfoundation.org/aboutepilepsy/whatisepilepsy/ statistics.cfm. Accessed April 17, 2011.

14. Buck D, Jacoby A, Baker GA, Chadwick DW. Factors influencing compliance with antiepileptic drug regimes. Seizure. 1997;6(2):87-93.

15. Epilepsy Foundation [homepage on the Internet]. Landover (MD): Epilepsy Foundation of America; 2010. Available from: http://www. epilepsyfoundation.org. Accessed April 17, 2011.

16. Faught E, Duh MS, Weiner JR, Guérin A, Cunnington MC. Nonadherence to antiepileptic drugs and increased mortality: findings from the RANSOM Study. Neurology. 2008;71(20):1572-1578.

17. Faught RE, Weiner JR, Guérin A, Cunnington MC, Duh MS. Impact of nonadherence to antiepileptic drugs on health care utilization and costs: findings from the RANSOM Study. Epilepsia. 2009;50(3):501-509.

18. Quan H, Sundararajan V, Halfon P, et al. Coding algorithms for defining comorbidities in ICD-9-CM and ICD-10 administrative data. Med Care. 2005;43(11):1130-1139.

19. Agency for Healthcare Research and Quality (AHRQ). Healthcare Cost and Utilization Project (HCUP). Available from: http://www.ahrq.gov/ data/hcup/. Accessed April 17, 2011.

20. Jonsson P, Eeg-Olofsson O. 10-Year outcome of childhood epilepsy in well-functioning children and adolescents. Eur J Paediatr Neurol. 2011;15(4):331-337.

21. Faught E. Monotherapy in adults and elderly persons. Neurology. 2007; 69(24 Suppl 3):S3-S9.

22. Modi AC, Guilfoyle SM, Morita DA, Glauser TA. Development and reliability of a correction factor for parent-reported adherence to pediatric antiepileptic drug therapy. Epilepsia. 2011;52(2):370-376.

23. Modi AC, Morita DA, Glauser TA. One-month adherence in children with new-onset epilepsy: white-coat compliance does not occur. Pediatrics. 2008;121(4):e961-e966.
24. Asato MR, Manjunath R, Sheth RD, et al. Adolescent and caregiver experiences with epilepsy. J Child Neurol. 2009;24(5):562-571.

25. Rubenstein S. Industry fights switch to generics for epilepsy. Wall Street Journal. July 13, 2007:A1-A10.

26. Kesselheim AS, Stedman MR, Bubrick EJ, et al. Seizure outcomes following the use of generic versus brand-name antiepileptic drugs: a systematic review and meta-analysis. Drugs. 2010;70(5):605-621.

27. Hodges S, Forsythe WI, Gillies D, Remington H, Cawood A. Bio-availability and dissolution of three phenytoin preparations for children. Dev Med Child Neurol. 1986;28(6):708-712.

28. Kishore K, Jailakhani BL, Sharma JN, Ahuja GK. Serum phenytoin levels with different brands. Indian J Physiol Pharmacol. 1986;30(2): $171-176$

29. Jumao-as A, Bella I, Craig B, Lowe J, Dasheiff RM. Comparison of steady-state blood levels of two carbamazepine formulations. Epilepsia. 1989;30(1):67-70.

30. Hartley R, Aleksandrowicz J, Bowmer CJ, Cawood A, Forsythe WI. Dissolution and relative bioavailability of two carbamazepine preparations for children with epilepsy. J Pharm Pharmacol. 1991;43(2):117-119.

31. Soryal I, Richens A. Bioavailability and dissolution of proprietary and generic formulations of phenytoin. J Neurol Neurosurg Psychiatry. 1992;55(8):688-691.

32. Wolf P, May T, Tiska G, Schreiber G. Steady state concentrations and diurnal fluctuations of carbamazepine in patients after different slow release formulations. Arzneimittelforschung. 1992;42(3):284-288.

33. Oles KS, Penry JK, Smith LD, Anderson RL, Dean JC, Riela AR. Therapeutic bioequivalency study of brand name versus generic carbamazepine. Neurology. 1992;42(6):1147-1153.

34. Silpakit O, Amornpichetkoon M, Kaojarern S. Comparative study of bioavailability and clinical efficacy of carbamazepine in epileptic patients. Ann Pharmacother. 1997;31(5):548-552.

35. Vadney VJ, Kraushaar KW. Effects of switching from Depakene to generic valproic acid on individuals with mental retardation. Ment Retard. 1997;35(6):468-472.
Pediatric Health, Medicine and Therapeutics

\section{Publish your work in this journal}

Pediatric Health, Medicine and Therapeutics is an international, peerreviewed, open access journal publishing original research, reports, editorials, reviews and commentaries. All aspects of health maintenance, preventative measures and disease treatment interventions are addressed within the journal. Practitioners from all disciplines are invited to submit

\section{Dovepress}

their work as well as healthcare researchers and patient support groups. The manuscript management system is completely online and includes a very quick and fair peer-review system. Visit http://www.dovepress. com/testimonials.php to read real quotes from published authors. 